\title{
BMJ Open Prevalence and risk of pre-eclampsia and gestational hypertension in twin pregnancies: a population-based register study
}

\author{
Katariina Laine, ${ }^{1,2}$ Gulim Murzakanova, ${ }^{1}$ Kristina Baker Sole, ${ }^{3}$ Aase Devold Pay, ${ }^{1}$
} Siri Heradstveit, ${ }^{1}$ Sari Räisänen ${ }^{4}$

To cite: Laine $K$, Murzakanova G, Sole KB, et al. Prevalence and risk of pre-eclampsia and gestational hypertension in twin pregnancies: a populationbased register study. BMJ Open 2019;9:e029908. doi:10.1136/ bmjopen-2019-029908

\section{- Prepublication history for} this paper is available online. To view these files please visit the journal online (http://dx.doi org/10.1136/bmjopen-2019029908).

Received 17 February 2019 Revised 12 May 2019 Accepted 11 June 2019

Check for updates

(C) Author(s) (or their employer(s)) 2019. Re-use permitted under CC BY-NC. No commercial re-use. See rights and permissions. Published by BMJ.

${ }^{1}$ Department of Obstetrics, Oslo Universitetssykehus, Oslo, Norway

${ }^{2}$ Medical Faculty, University of Oslo, Oslo, Norway

${ }^{3}$ Faculty of Medicine, Universitetet i Oslo, Oslo, Norway

${ }^{4}$ School of Health Care and Social Service, Tampereen ammattikorkeakoulu, Tampere, Finland

Correspondence to

Dr Katariina Laine;

kattiksen@yahoo.no

\section{ABSTRACT}

Objectives The aim of this study was to assess the prevalence and risk of pre-eclampsia and gestational hypertension in twin pregnancies compared with singleton pregnancies.

Design Population-based cohort study.

Setting Medical Birth Registry of Norway and Statistics

Norway.

Participants 929963 deliveries with 16174 twin pregnancies in 1999-2014.

Methods Pre-eclampsia prevalences in twin and singleton pregnancies were described in percentages. Multivariable regression analyses were performed to assess the risks of pre-eclampsia and gestational hypertension in twin pregnancies compared with those in singleton pregnancies, adjusted for previously known risk factors. Primary and secondary outcome measures Prevalence and risk of pre-eclampsia and gestational hypertension. Results The prevalence of pre-eclampsia in the study population was $3.7 \%$ (3.4\% in singleton pregnancies, $11.8 \%$ in twin pregnancies $(\mathrm{p}=0.001))$. The $\mathrm{OR}$ for pre-eclampsia in twin pregnancies was three to fourfold compared with singleton pregnancies (OR $3.78 ; 95 \% \mathrm{Cl} 3.59$ to 3.96 ). After adjustment for known risk factors, twin pregnancy remained an independent risk factor for pre-eclampsia (adjusted OR 4.07; 95\% $\mathrm{Cl} 3.65$ to 4.54). The prevalence of gestational hypertension was $1.7 \%$ in women with singleton pregnancies and $2.2 \%$ in those with twin pregnancies (OR $1.27 ; 95 \% \mathrm{Cl} 1.14$ to 1.41 ). After adjustment for known risk factors, gestational hypertension was not significantly associated with twin pregnancy.

Conclusions The risk of pre-eclampsia in twin pregnancies was three to fourfold compared with singleton pregnancies, regardless of maternal age, parity, educational level, smoking, maternal comorbidity or in vitro fertilisation. The risk of gestational hypertension was not increased in women with twin pregnancies after adjustment for the main risk factors.

\section{INTRODUCTION}

Hypertensive disorders are among the most common complications occurring during pregnancy and one of the most common reasons for maternal and fetal mortality and morbidity globally. The aetiology of pre-eclampsia (PE)
Strengths and limitations of this study

The study is based on a large population-based register, consisting of 929963 deliveries with 16174 twin pregnancies.

- This is the largest study assessing pre-eclampsia and gestational hypertension in twin pregnancies.

- Multivariable logistic regression analysis with calculation of adjusted ORs was performed to explore associations between exposures and outcomes.

- Maternal weight and height were not registered in the data source in the beginning of the study period, thus, body mass index is analysed in a subgroup of 219435 pregnancies.

- Chorionicity of the twins is not reported in the Norwegian Birth Registry.

and gestational hypertension $(\mathrm{GH})$ remains unknown, but many risk factors have been identified. The risk of PE is higher among nulliparous women compared with parous women. Advanced maternal age, obesity, diabetes mellitus and prepregnancy hypertension increase the risk of PE. Risk factors for GH are similar in part to those for PE. ${ }^{1-3}$

Prior studies have identified twin pregnancy as a risk factor for $\mathrm{PE},{ }^{4-7}$ and the increased PE risk and prevalence in twin pregnancies may be associated to larger placental mass, associated with higher levels of circulating placental markers. ${ }^{8}$ Large population-based studies conducted with multiple gestation as the main exposure to quantify the prevalence and risk of PE are lacking. In previous studies assessing the prevalence of PE twin pregnancies are commonly excluded ${ }^{9-12}$ or PE risk is analysed either separately in twin and singleton pregnancies ${ }^{6}$ or only twins are included in a risk assessment. ${ }^{13}$ When assessing the risk factors for PE, a small study population and 
low number of twin pregnancies may hamper the interpretation of results. ${ }^{114}$

The risk of GH in twin pregnancy is even less studied. Thus, the aim of this study was to determine the prevalence and assess the risk of PE and GH in twin pregnancies compared with singleton pregnancies.

\section{METHODS}

This study is a part of the PURPLE Study, a large epidemiological study assessing adverse pregnancy outcomes in Norway during the last decades, by linking two population registries: Medical Birth Registry of Norway (MBRN) and Statistics Norway (SSB). The researchers used only anonymous data.

Since this is a register study, no patient involvement was relevant in this study.

\section{Data sources}

The MBRN contains data on all births, including home births, occurring in Norway since 1967. Maternal pre-pregnancy health and changes in health conditions during pregnancy are recorded using standardised maternity health cards (which are similar throughout the country) during antenatal visits. This information, in addition to maternal, fetal and obstetrical data from labour and delivery, is collected on a standardised form immediately after each delivery by the midwife in charge of the labour suite or attending a home birth and reported to the MBRN. Paediatricians record information on newborns admitted to neonatal intensive care units and report these data to the MBRN. Such reporting is mandatory and thus covers all births in Norway. All births are also routinely reported to the Central Population Register for the purpose of obtaining personal ID numbers, which are assigned to all inhabitants of Norway and can be used to link and merge data from different health registries.

The SSB is a central agency that produces official statistics for Norway, such as those for residents' education, county of residence, country of birth and immigrant status. MBRN and SSB data were linked to obtain information on maternal education for this study.

\section{Study population}

The study population consisted of women who gave birth during the years 1999-2014 in Norway (929 963 deliveries). Deliveries before the 22nd week of gestation and pregnancies longer than 43 weeks in duration were excluded because of the probability of error in real pregnancy duration. Multiple gestations with more than two fetuses were also excluded.

\section{Variable definitions}

We studied two outcomes: PE and GH. PE was defined as hypertension (systolic blood pressure (BP) $\geq 140 \mathrm{~mm}$ $\mathrm{Hg}$ and/or diastolic $\mathrm{BP} \geq 90 \mathrm{~mm} \mathrm{Hg}$ ) and proteinuria ( $\geq 0.3 \mathrm{~g} / 24$ hours or $\geq 1+$ on urine dipstick in two measurements) occurring after 20 weeks of gestation. GH was defined as a hypertension ( $\mathrm{BP} \geq 140 / 90 \mathrm{~mm} \mathrm{Hg}$ ) without proteinuria, occurring during pregnancy in the absence of prepregnancy hypertension.

We assessed well-known risk factors for PE and hypertension, such as maternal age, parity, body mass index (BMI), diabetes and smoking. We also evaluated less-studied factors, such as socioeconomic status (educational level was used as a proxy) and in vitro fertilisation (IVF).

The main exposure was twin pregnancy. All pregnant women in Norway are offered routine second-trimester ultrasound examination free of charge, and 99\% of women undergo this examination, during which gestational age and number of fetuses are determined. All twin pregnancies are followed further in hospitals providing specialist obstetric care.

The MBRN has collected data on maternal weight and height, enabling calculation of the BMI, since 2006. The proportion of weights and heights recorded has increased from year to year, achieving more than $70 \%$ coverage for the latest study years. Maternal weight and height were recorded for 24\% (219 435) of the entire study population. Using WHO definitions, mothers were classified as underweight $\left(\mathrm{BMI}<18.5 \mathrm{~kg} / \mathrm{m}^{2}\right)$, normal weight $\left(\mathrm{BMI}=18.5-24.9 \mathrm{~kg} / \mathrm{m}^{2}\right)$, overweight $(\mathrm{BMI}=25-29.9 \mathrm{~kg}$ / $\mathrm{m}^{2}$ ) and obese (BMI $\geq 30 \mathrm{~kg} / \mathrm{m}^{2}$ ).

Educational levels are recorded by the SSB following the eight-level Norwegian Standard Classification of Education. We recategorised maternal education using four levels based on duration (in years): none or compulsory education only (through 10th grade); secondary education (11-14th grade, used as the reference); bachelor-level education; and master/PhD-level education.

MBRN records information on IVF pregnancies based on a mandatory notification from institutions offering IVF treatment in Norway. IVF treatment was categorised as either 'yes' or 'no'.

Maternal smoking status (categorised as 'no', 'sometimes' or 'daily') was recorded on maternity health cards at the beginning of pregnancy during the first antenatal visit, and reported to the MBRN after delivery. We, thus, retrieved this information from MBRN records.

\section{Statistical analysis}

Continuous data were categorised. Descriptive statistics were used to characterise the prevalence of PE and GH in subgroups of women according to maternal and obstetrical characteristics. Unadjusted ORs were determined by logistic regression analysis. Crude ORs with $95 \%$ CIs and $\mathrm{p}$ values were used to identify significant risk factors for further analysis. $P$ values $<0.01$ were defined as significant. Multivariable logistic regression analysis with calculation of adjusted ORs (aORs) was performed to explore associations between exposures and outcomes. Two multivariable regression models were constructed to assess covariation between different risk factors. In model 1 , all significant variables except maternal BMI were 
Table 1 Maternal and pregnancy characteristics in the study population

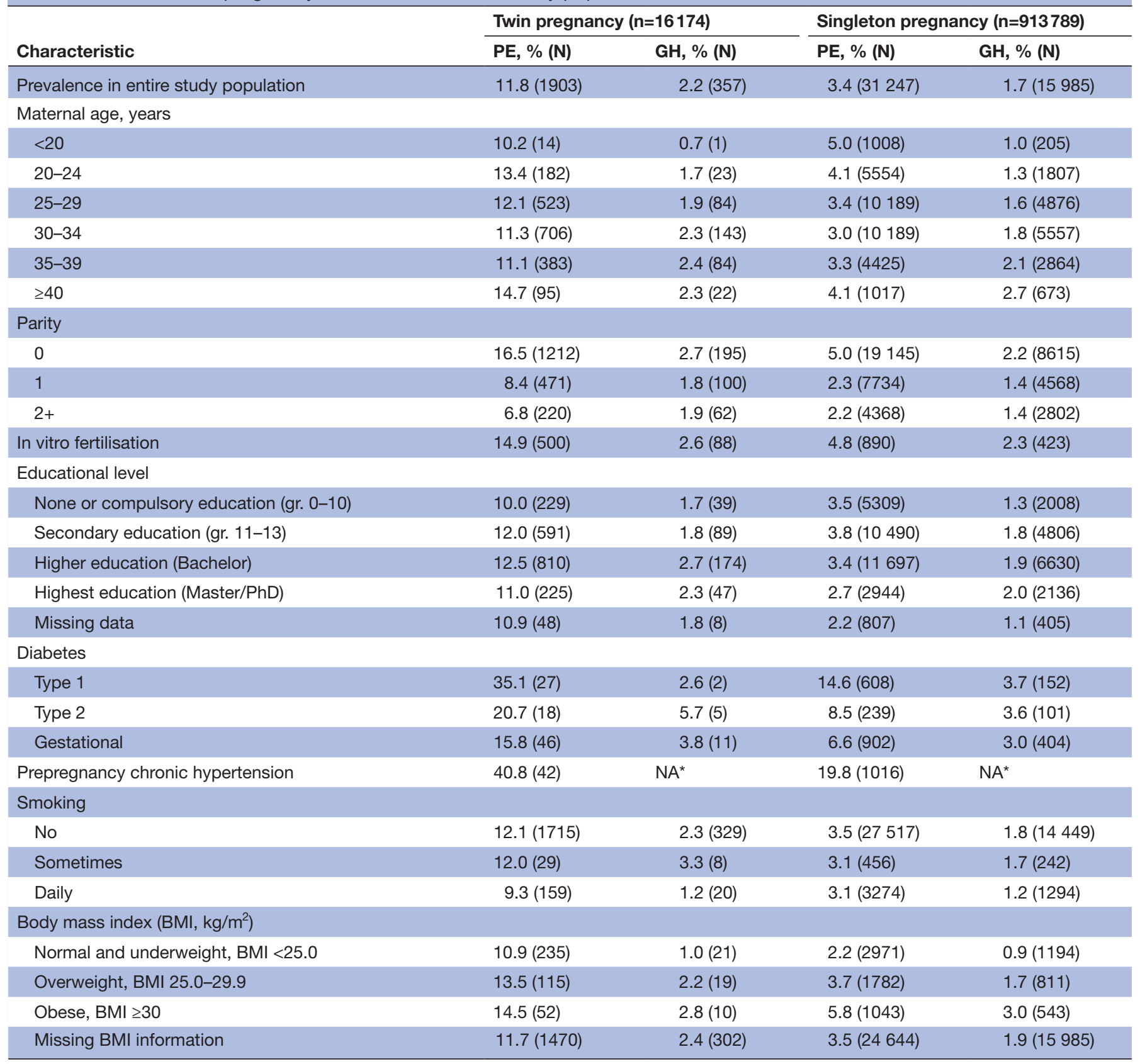

The prevalence of pre-eclampsia (PE) and gestational hypertension $(\mathrm{GH})$ in the subgroups of women for each variable is presented in percentages. Number of women with PE or GH presented in brackets, $n=929963$.

${ }^{*} \mathrm{NA}$, not applicable.

included. Model 2 consisted of data from the 219435 women with recorded BMIs. IBM SPSS Statistics V.24 was used to perform the analyses. No interaction or multicollinearity between the variables was found when carefully tested in SPSS.

A risk index was calculated using four main exposures: advanced maternal age ( $\geq 35$ years), any diabetes (type 1 , type 2 or gestational), nulliparity and BMI $>29 \mathrm{~kg} / \mathrm{m}^{2}$. A sensitivity analysis was performed with different categories of the included risk factors: different maternal ages and BMI categories and type 1 diabetes.
Attributable risk was calculated based on prevalence of $\mathrm{PE}$ in twin pregnancies and singleton pregnancies.

\section{Patient and public involvement}

In this register-based study, patients/users were not involved in the planning, design or conduct of the study.

\section{RESULTS}

PE was three to fourfold more prevalent among women with twin pregnancies compared with women with singleton pregnancies. The attributable risk for $\mathrm{PE}$ 


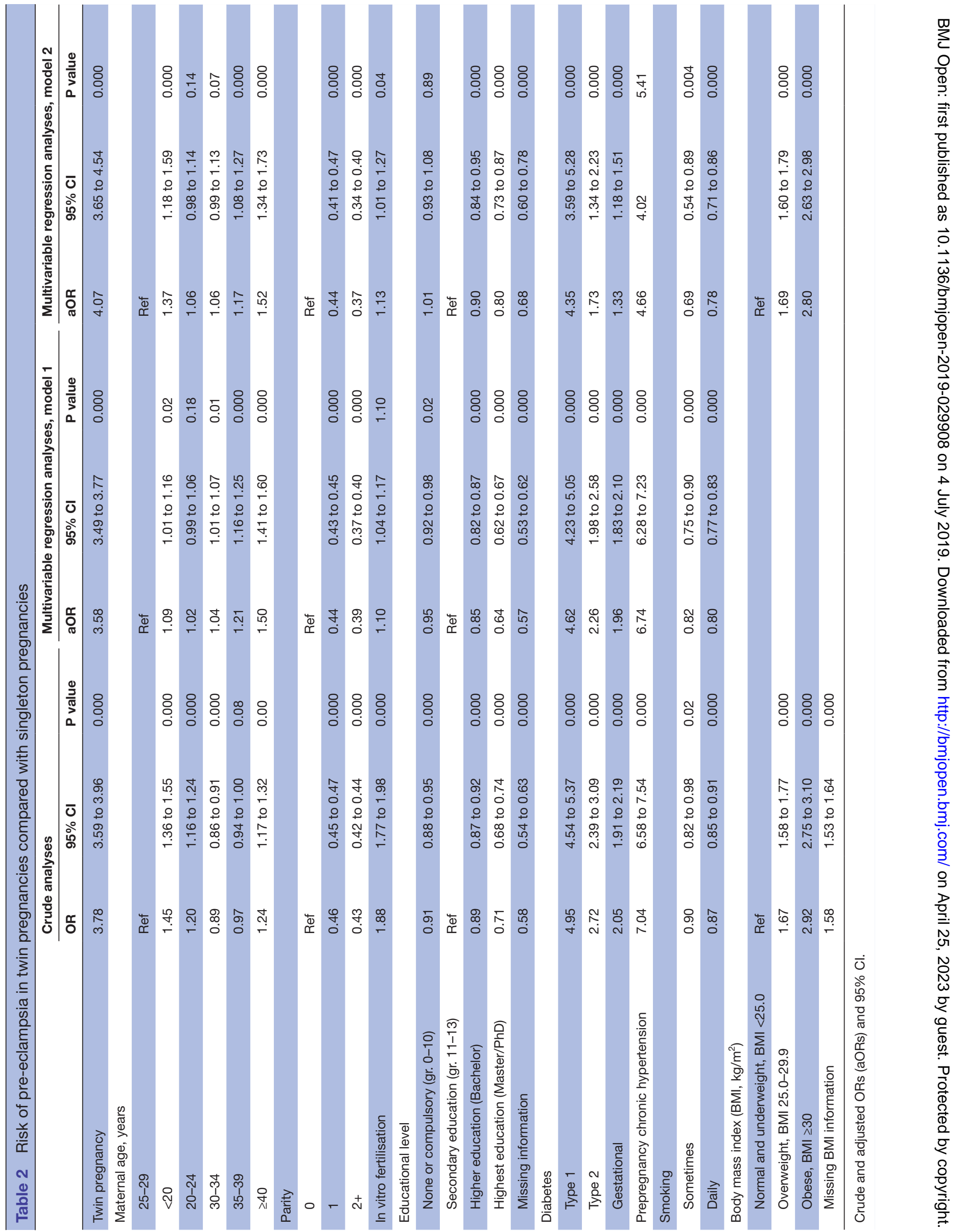




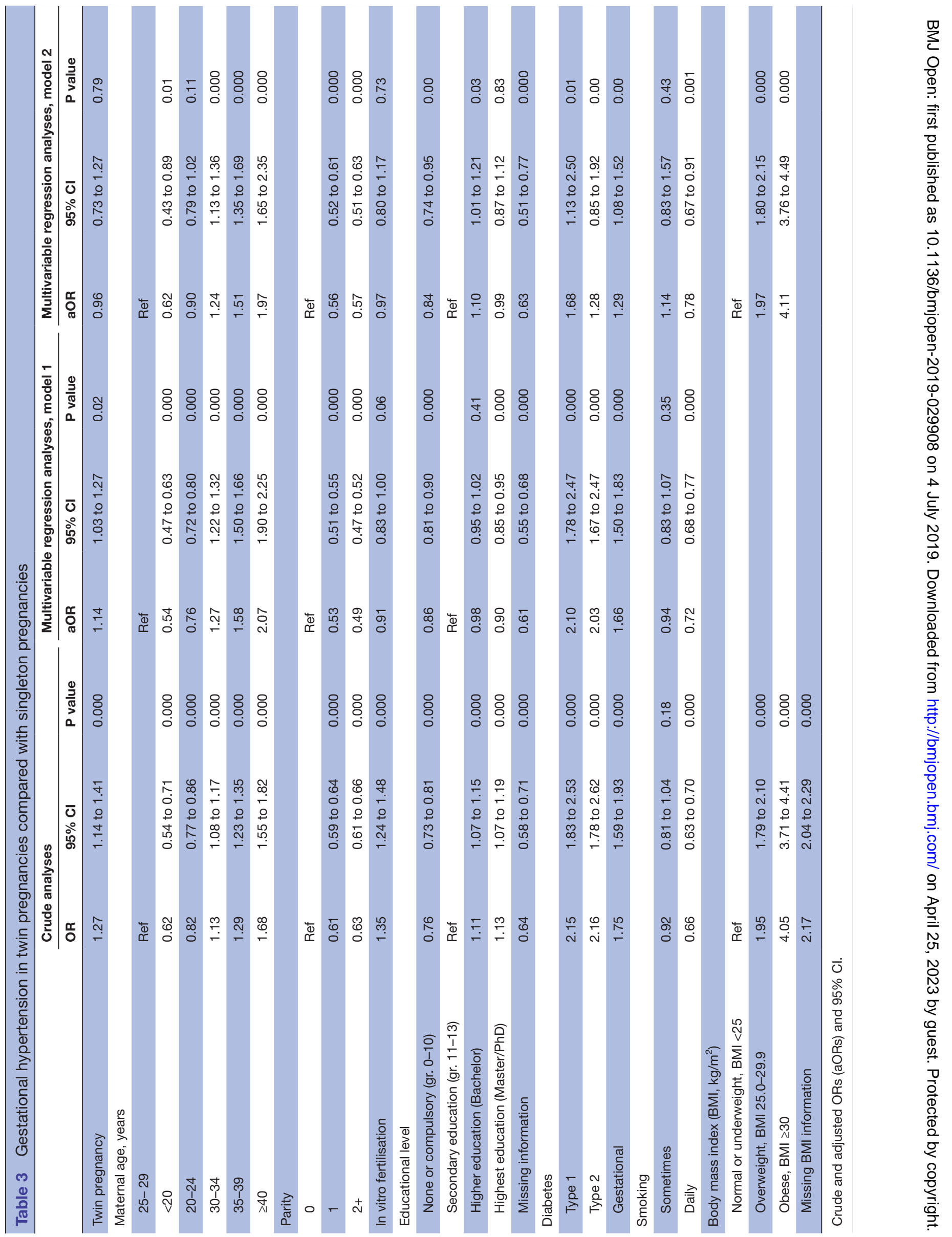




\begin{tabular}{lcc} 
Table 4 & \multicolumn{2}{c}{ Risk index for pre-eclampsia } \\
\cline { 2 - 3 } $\begin{array}{l}\text { Risk index } \\
\text { score }\end{array}$ & $\begin{array}{l}\text { Prevalence of pre-eclampsia, \% } \\
\text { pregnancies }\end{array}$ & $\begin{array}{l}\text { Singleton } \\
\text { pregnancies }\end{array}$ \\
\hline 0 & 7.2 & 2.0 \\
1 & 13.5 & 4.1 \\
2 & 17.8 & 6.5 \\
3 & 20.0 & 10.1 \\
4 & 30.8 & 13.4 \\
\hline
\end{tabular}

Risk index score is the number of risk factors present among the following: maternal age $\geq 35$ years, nulliparity, diabetes type 1,2 or gestational diabetes, $\mathrm{BMI}>29 \mathrm{~kg} / \mathrm{m}^{2}$.

$\mathrm{BMI}$, body mass index.

associated with twin pregnancy was $8.4 \%$, the prevalence of PE was $71.2 \%$ higher in twin pregnancies compared with singleton pregnancies. Three to fourfold difference in prevalence was observed in most subgroups of women defined by parity, age, education, smoking status or BMI. Among women with type 1 diabetes and twin pregnancies, the prevalence of PE was 2.4-fold greater than that among women with type 1 diabetes and singleton pregnancies (table 1).

The unadjusted regression analysis confirmed the same pattern; the unadjusted OR for PE in women with twin pregnancies, calculated using women with singleton pregnancies as the reference, was 3.78 (95\% CI 3.59 to 3.96). In the multivariable regression analysis including significant covariates, twin pregnancy remained a strong and independent risk factor for PE (aOR 3.58; 95\% CI 3.49 to 3.77 ). A similar result was obtained with the inclusion of maternal BMI (aOR 4.07; 95\% CI 3.65 to 4.54). Twin pregnancy, prepregnancy chronic hypertension, type 1 diabetes and obesity were the strongest risk factors for PE (table 2).

GH was also more prevalent among women with twin pregnancies, but the difference was of a lesser magnitude than for PE. In the crude analysis, the risk of GH was increased by $27 \%$ (OR 1.27; 95\% CI\% 1.14 to $1.41 \%$ ) among women with twin pregnancies compared with those with singleton pregnancies. In model 1 of the multivariable regression analysis, this difference was reduced to $14 \%$ (aOR 1.14; 95\% CI $1.03 \%$ to $1.27 \%$ ), and in model 2 , it was absent (aOR $0.96 ; 95 \%$ CI 0.73 to 1.27 ). Obesity, advanced maternal age ( $>40$ years) and type 1 diabetes were the strongest risk factors for GH (table 3).

The risk index calculated from main risk factors (maternal age $\geq 35$ years, nulliparity, diabetes type 1,2 or gestational diabetes, BMI $>29 \mathrm{~kg} / \mathrm{m}^{2}$ ) showed that a combination of several risk factors in one woman increased the prevalence of $\mathrm{PE}$, with twin pregnancies having a two to fourfold increased prevalence of PE compared with singleton pregnancies (table 4). A sensitivity analysis was conducted with different subcategories (advanced maternal age $\geq 40$ years, $\mathrm{BMI} \geq 35$ and diabetes type 1 only) in the risk index model and yielded an even greater prevalence of PE (data not shown).

\section{DISCUSSION}

The main finding of this study was that twin pregnancy was a strong independent risk factor for PE, and the risk remained significant after adjustment for other known risk factors for PE. The combined presence of multiple risk factors further increased the prevalence of PE.

To our knowledge, this is the largest epidemiological study assessing the prevalence and risk of PE and GH in women with twin pregnancies compared with singleton pregnancies. Our study found that the risk of PE in twin pregnancy is higher than previously reported. Smaller studies have previously investigated twin pregnancy as the main exposure for PE risk. Sibai et a $\tilde{\varphi}$ compared 684 twin pregnancies with 2946 singleton pregnancies and found a similar trend as in our study, but the estimation of increased risk of PE in twin pregnancies was less than what our study found (aOR 2.48, 95\% CI 1.82 to 3.38).

A systematic review and meta-analysis of risk factors for PE yielded an unadjusted relative risk of 2.9 (95\% CI 2.6 to 3.1$).{ }^{15}$ In this large meta-analysis, only 8 of 92 articles included multiple gestations as a risk factor for PE, confirming the paucity of studies estimating the association between twin pregnancies and PE.

The association between twin pregnancy and GH was less prominent and the association disappeared in the multivariable regression analysis. This is in line with a previous review from Krotz et al showing high relative risks for $\mathrm{PE}$ and lower for $\mathrm{GH}$ when twin and singleton pregnancies were compared. ${ }^{16}$ This may indicate that $\mathrm{PE}$ and GH have a different aetiology. However, some women with non-proteinuric PE may be classified as GH in our study. Such misclassification of PE would not cause false positive associations, but would rather strengthen the association between $\mathrm{GH}$ and twin pregnancy in our analyses.

The main strength of our study was the large study population, which included 16174 twin pregnancies, of which 2260 were complicated by PE or GH. A 1998 Swedish study of 10659 nulliparous women, including 78 multiple births, showed results similar to our study. Only 4 women with multiple gestation in the study had GH, and 14 had PE. ${ }^{1}$

Another strength was the use of reliable population-based data, which reduced the bias; the MBRN is considered to be a high-quality clinical data registry suitable for research. ${ }^{1718}$ The large study population enabled us to investigate the infrequent event of twin pregnancy as the main exposure. Many previous studies exploring hypertensive disorders in pregnancy have involved only the assessment of PE, with no information on the prevalence of or risk factors for $\mathrm{GH}$.

One weakness of our study was that information on twins' chorionicity was lacking. Previous studies, however, have yielded conflicting results regarding chorionicity 
and PE. Some previous studies have shown an increased risk of $\mathrm{PE}$ in women bearing dichorionic twins (DC) compared with those bearing monochorionic twins (MC). Bartnik et al studied $233 \mathrm{DC}$ and $79 \mathrm{MC}$ twin pregnancies and showed a three to fourfold increased risk of PE in DC pregnancies. Sparks et al studied 492 DC and 203 MC twin pregnancies and found a doubled prevalence of $\mathrm{PE}$ among women with dichorionic twin pregnancy. ${ }^{19}{ }^{20}$ In contrast, Savvidou et al found no difference in the risk of PE between monochorionic and dichorionic twins in a study with 666 twin pregnancies. ${ }^{21}$ In a prospective study of Francisco et al with 1789 twin pregnancies, a similar relative risk for preterm PE was observed in ongoing DC and MC twin pregnancies. ${ }^{4}$

Because data on maternal BMI were not recorded in the early years of the study, the analyses were performed with two models to test the effect of BMI on the risk of $\mathrm{PE}$ and $\mathrm{GH}$ in twin pregnancies. Prevalence of PE and $\mathrm{GH}$ for the group of women missing information on $\mathrm{BMI}$ is presented in table 1. Although high BMI was a contributing risk factor for PE and GH, including BMI in the regression analysis did not substantially change the results.

Generally, a very small amount of information was missing from our variables, with the exception being information about smoking: Early pregnancy smoking status was not recorded in $16 \%$ of the study population. In our analysis, women lacking data on smoking status were categorised as non-smokers, as in two previous studies based on MBRN data. ${ }^{11}{ }^{12}$ Data on educational level were missing for $3.9 \%$ of the study population, and this group was analysed separately and presented in all tables. For all other variables, the frequency of missing data was less than $0.1 \%$.

Based on our findings, we present a novel risk index for PE prevalence that shows the addition of known risk factors for PE having a multiplicative effect in twin pregnancies. Our risk index is based on maternal characteristics easily recorded during routine antenatal care, and does not require any invasive or high-technology testing.

\section{CONCLUSION}

Twin pregnancy was an independent risk factor PE, even after adjustment for other previously known risk factors. Quantification of PE prevalence and risk (using a risk index) may help clinicians identify high-risk twin pregnancies in need of close specialist follow-up. With a notably increased risk of PE, prophylactic aspirin treatment should be offered when a twin pregnancy is detected in the first trimester. ${ }^{22-24}$

Contributors KL: Is the principal investigator of the PURPLE Study, planned the study, performed the data analyses, wrote the first draft of the manuscript. GM: Contributed for the design of the study, interpreted the results, drafted and revised the manuscript and accepted the last version of the manuscript. KBS: Contributed in the acquisition of the data, contributed the management of the raw data, interpreted the results, drafted and revised the manuscript and accepted the last version of the manuscript. ADP: Contributed for the planning of the study, interpreted the results, wrote parts of the manuscript and accepted the last version of the manuscript. SH: Carried out the search and analysis of the literature, contributed in the planning of the study, drafted the manuscript of the study and accepted the last version of the manuscript. SR: Planned the study, interpreted the results, participated in the writing and finalising the manuscript and accepted the last version of the manuscript.

Funding This work was supported by the Norwegian SIDS and Stillbirth Society, grant number 554.04/14.

Disclaimer The funding source had no role in the design of the study; collection, analysis and interpretation of the data, in writing of the report or submission of the article to BMJ Open.

Competing interests None declarerd.

Patient consent for publication Not required.

Ethics approval The study was approved by the regional ethics committee in south-eastern Norway (ref. 2015/681) and the Personal Data Officer of Oslo University Hospital, Oslo, Norway. The study was based on anonymised data from the Medical Birth Registry of Norway (MBRN) and Statistics Norway (SSB). All parts of the study followed the regulations of the Norwegian Health Research legislation.

Provenance and peer review Not commissioned; externally peer reviewed.

Data sharing statement № additional data will be available, due to the regulations of the Norwegian Health Research legislation.

Open access This is an open access article distributed in accordance with the Creative Commons Attribution Non Commercial (CC BY-NC 4.0) license, which permits others to distribute, remix, adapt, build upon this work non-commercially, and license their derivative works on different terms, provided the original work is properly cited, appropriate credit is given, any changes made indicated, and the use is non-commercial. See: http://creativecommons.org/licenses/by-nc/4.0/.

\section{REFERENCES}

1. Ros HS, Cnattingius S, Lipworth L. Comparison of risk factors for preeclampsia and gestational hypertension in a population-based cohort study. Am J Epidemiol 1998;147:1062-70.

2. Roberts CL, Ford JB, Algert CS, et al. Population-based trends in pregnancy hypertension and pre-eclampsia: an international comparative study. BMJ Open 2011;1:e000101-2011.

3. Shen M, Smith GN, Rodger M, et al. Comparison of risk factors and outcomes of gestational hypertension and pre-eclampsia. PLoS One 2017;12:e0175914.

4. Francisco $C$, Wright $D$, Benkő $Z$, et al. Hidden high rate of preeclampsia in twin compared with singleton pregnancy. Ultrasound Obstet Gynecol 2017;50:88-92.

5. Sibai BM, Hauth J, Caritis S, et al. Hypertensive disorders in twin versus singleton gestations. National Institute of Child Health and Human Development Network of Maternal-Fetal Medicine Units. Am J Obstet Gynecol 2000;182:938-42.

6. Coonrod DV, Hickok DE, Zhu K, et al. Risk factors for preeclampsia in twin pregnancies: a population-based cohort study. Obstet Gynecol 1995;85(5 Pt 1):645-50.

7. Long PA, Oats JN. Preeclampsia in twin pregnancy--severity and pathogenesis. Aust N Z J Obstet Gynaecol 1987;27:1-5.

8. Bdolah Y, Lam C, Rajakumar A, et al. Twin pregnancy and the risk of preeclampsia: bigger placenta or relative ischemia? Am J Obstet Gynecol 2008;198:428.e1-6.

9. Sibai BM, Gordon T, Thom E, et al. Risk factors for preeclampsia in healthy nulliparous women: a prospective multicenter study. The National Institute of Child Health and Human Development Network of Maternal-Fetal Medicine Units. Am J Obstet Gynecol 1995;172(2 Pt 1):642-8.

10. Klungsøyr K, Morken NH, Irgens L, et al. Secular trends in the epidemiology of pre-eclampsia throughout 40 years in Norway: prevalence, risk factors and perinatal survival. Paediatr Perinat Epidemiol 2012;26:190-8.

11. Ebbing C, Rasmussen S, Skjaerven R, et al. Risk factors for recurrence of hypertensive disorders of pregnancy, a populationbased cohort study. Acta Obstet Gynecol Scand 2017;96:243-50.

12. Sole KB, Staff AC, Laine K. The association of maternal country of birth and education with hypertensive disorders of pregnancy: A population-based study of 960516 deliveries in Norway. Acta Obstet Gynecol Scand 2018;97:1237-47.

13. Lučovnik M, Tul N, Verdenik I, et al. Risk factors for preeclampsia in twin pregnancies: a population-based matched case-control study. J Perinat Med 2012;40:379-82. 
14. Odegård RA, Vatten LJ, Nilsen ST, et al. Risk factors and clinical manifestations of pre-eclampsia. BJOG 2000;107:1410-6.

15. Bartsch E, Medcalf KE, Park AL, et al. Clinical risk factors for preeclampsia determined in early pregnancy: systematic review and meta-analysis of large cohort studies. BMJ 2016;353:11753.

16. Krotz S, Fajardo J, Ghandi S, et al. Hypertensive disease in twin pregnancies: a review. Twin Res 2002;5:8-14.

17. Langhoff-Roos J, Krebs L, Klungsøyr K, et al. The Nordic medical birth registers--a potential goldmine for clinical research. Acta Obstet Gynecol Scand 2014;93:132-7.

18. Thomsen LC, Klungsøyr K, Roten LT, et al. Validity of the diagnosis of pre-eclampsia in the Medical Birth Registry of Norway. Acta Obstet Gynecol Scand 2013;92:943-50.

19. Bartnik P, Kosinska-Kaczynska K, Kacperczyk J, et al. Twin Chorionicity and the Risk of Hypertensive Disorders: Gestational Hypertension and Pre-eclampsia. Twin Res Hum Genet 2016;19:377-82.
20. Sparks TN, Cheng YW, Phan N, et al. Does risk of preeclampsia differ by twin chorionicity? J Matern Fetal Neonatal Med 2013;26:1273-7.

21. Savvidou MD, Karanastasi E, Skentou C, et al. Twin chorionicity and pre-eclampsia. Ultrasound Obstet Gynecol 2001;18:228-31.

22. Rolnik DL, Wright D, Poon LC, et al. Aspirin versus placebo in pregnancies at high risk for preterm preeclampsia. N Engl J Med 2017;377:613-22.

23. Euser AG, Metz TD, Allshouse AA, et al. Low-dose aspirin for pre-eclampsia prevention in twins with elevated human chorionic gonadotropin. J Perinatol 2016;36:601-5.

24. Caspi E, Raziel A, Sherman D, et al. Prevention of pregnancyinduced hypertension in twins by early administration of low-dose aspirin: a preliminary report. Am $J$ Reprod Immunol 1994;31:19-24. 